\title{
MODERN TRANSDERMAL TERAPÖTIK SISTEMLERIN TEDAVIDEKİ YERI
}

\author{
MODERN TRANSDERMAL THERAPEUTIC SYSTEMS IN MEDICATION
}

\section{Özge İNAL, Evren ALĞIN YAPAR, Tamer BAYKARA*}

Ankara University, Faculty of Pharmacy, Department of Pharmaceutical Technology, 06100 Tandoğan-Ankara, TURKEY

\section{ÖZET}

Modern transdermal terapötik sistemler gelişim sürecinde, özellikle oral yoldan verilemeyen veya verilişinde fazla miktarda kayıplar yaşanan etkin maddelerin verilişi amactyla geliştirilen sistemlerdir. Bu sistemlerin en önemli avantajlar arasında uzun süreli etki elde edilmesi ve etki veya yan etkinin istendiği anda sonlandirlabilmesi yer almaktadir. Transdermal sistemlerin en önemli dezavantajlarindan biri ise fizikokimyasal özellikleri nedeniyle birçok etkin maddenin bu yolla verilememesidir. Bu problem kimyasal, fiziksel ya da mekanik geçiş arttırıcı mekanizmaların yardımıyla çözülmeye çalışllmaktadır. Özellikle fiziksel ve mekanik yöntemlerden yararlanılan çalışmalar son yıllarda gündemdedir. Ancak, bu mekanizmaların üretim maliyetlerinin yüksek olması ve uygulandıkları alandaki güvenirliliklerinin tartışmalı olması dezavantajları bulunmaktadır. Bu nedenle de piyasada hala çok sayıda ticari transdermal cihaz olmadı̆̆ görülmektedir. Bu derlemede, 2009 yllında piyasada bulunan veya üzerinde klinik çallşmaları henüz devam eden ve elektriksel (iyontoforez, elektroforez, sonoforez), fiziksel (termal soyma, mikroiğneler) ya da mekanik (basınç dalgası) yöntemler ile geçiş arttıran transdermal ürün ve cihazlardan bahsedilmektedir.

Anahtar kelimeler: Transdermal, Geçiş yöntemleri, Terapötik sistemler, Ticari ürünler.

\section{ABSTRACT}

In their evaluation period, modern transdermal therapeutic systems have been evaluated for the delivery of active agents which can not be given especially by oral route or having loss on this route. The 
major advantage of these systems are to obtain long term effect and to finish the effect or side effects, when it is necessary. One of the major disadvantage of transdermal systems is that many of the active agents can not be given by transdermal route related with their physicochemical properties. This problem has been trying to be solved by using chemical, physical or mechanical penetration enhancement mechanisms. Especially, physical and mechanical methods are on the agenda of the late years. However, these methods have the disadvantages of high production costs and the controversial safety on application areas. Thus, it can be seen that still there is not so many commercial transdermal devices on the market. In this rewiev, transdermal products and devices which are commercial in 2009 or still evaluated clinically and using electrical (iontophoresis, electrophoresis, sonophoresis), physical (thermal ablation, microneedles) or mechanical (pressure wave) penetration enhancement mechanisms were discussed.

Key words: Transdermal, Penetration methods, Therapeutic systems, Commercial dosage forms/ products.

\section{GİRIŞ̧}

Ağız yoluyla alındığında gastrointestinal sistemde etkinliğini kaybeden ya da karaciğerde ilk geçiş etkisine uğrayan ilaçların deriden emilerek sistemik dolaşıma karışacak şekilde uygulanması fikri oldukça eskidir. Ancak bu klasik uygulama şeklinde, uygulanacak ilacın mutlak miktarı ve uygulanan yüzey alanının değişmesi sonucu ilacın tekrarlanabilir dozda verilmesi zorlaşmaktadır (1). Oysa transdermal terapötik sistemlerde ilaç depolanmış sistem, deri üzerine yerleştirilmekte ve sistemin taşıdı̆̆ı ilaç, kontrollü bir şekilde serbestleştirilerek deri üzerinden sistemik kan dolaşımına ulaşmaktadır. Bu tür sistemlerde ilaç dağıtım hızının sistem tarafindan kontrol edilmesi amaçlanmaktadır (1).

\section{DERIDEN GEÇIŞ}

\section{Deriden Geçiş Mekanizması}

Anatomik olarak deri, kompleks yapıda değişik fonksiyonları ve düzeni olan pek çok tabakadan (temel olarak epidermis, dermis, hipodermis tabakalarından) oluşmuştur. Deri yoluyla verilen etkin maddeler geçtikleri her tabakada farklı derecelerde olmak üzere ayrı bir bariyer etkisiyle karsılaşırlar. Ana bariyer epidermis tabakasının en üst katmanı olan stratum corneum tabakasıdır. Stratum corneum 'un ana hücresel materyalleri proteinler, lipidler ve suyun çeşitli kombinasyonlarından oluşmakta ve \% 75'e varan oranda su tutabilme özelliği nedeniyle kuru halde $15 \mu \mathrm{m}$ kalınlıkta iken, su alarak $48 \mu \mathrm{m}$ 'ye şişebilmektedir. Ayrıca stratum corneum tabakasının önemli derecede mekanik bir direnci de bulunmaktadır (2-4). 
Deriden kimyasal maddelerin geçişi üç temel yolla olmaktadır;

a) maddenin intrasellüler sıvıda çözünerek difüzyonu,

b) intersellüler sıvıdan difüzyonu,

c) deri yüzeyinde bulunan yapılardan (kıl folikülleri, ter ve yağ bezleri gibi) geçişi (4).

Perkütan absorbsiyon (deriden emilme), yerel uygulanan bir dozaj şeklinden ilacın salınması, deriye penetrasyonu ve daha sonra kılcallar vasıtasıyla kan dolaşımına katılmasıdır. Bu yollardan her biri, geçen molekülün tabiatına göre etkili olmaktadır. İlaçların deriden geçişleri çoğunlukla hücreler içinden olmaktadır, ancak geçiş yollarının birkaçı bir arada da gözlenebilmektedir. Örneğin; Stratum corneum vasıtasıyla epidermis tabakasına açılan kıl kökleri, ter ve yağ bezlerinin de emilimde belli ölçüde rolleri bulunmaktadır. Bilhassa kıl folükülü içindeki ince epidermadan emilim oldukça yüksektir. Stratum corneum tabakasının mekanik direnci nedeniyle alternatif olarak k1l foliküllerinden iyontoforez, elektroforez gibi yöntemler yardımıyla deriden etkin madde penetrasyonu çalışmaları son yıllarda yoğunluk kazanmıştır (2-5).

Deriden ilaç verilişinin en önemli avantajı etkin maddenin karaciğer ilk geçiş etkisinden ve gastrointestinal sistemde zarar görmesinden korunmuş olmas1, ayrıca etkin maddenin bizzat kendisinin de gastrointestinal sisteme zarar vermesi olasılığının önlenmesidir. Hasta uyuncunun artması da bir diğer avantajıdır. En önemli dezavantaj ise, her kimyasal maddenin deriden geçememesidir (6,7). Ayrıca transdermal yoldan sistemik etki elde edebilmek için deriden yüksek dozlarda uygulanan etkin maddelerin uygulama bölgesinde toksik ya da yan etkiler (iritasyon, duyarlı1ık) meydana getirmesi muhtemeldir. Çoğu durumda basit matris tipi yamalar yardımı ile derinin kendisinin sistemik dolaşıma katılacak etkin maddenin geçişini kontrol etmesi sağlanmaktadır. Deri üzerindeki yamaların, klasik oral dozlama ile karşılaştırılınca, etki süresinin sonuna kadar düzenli etkin madde kan düzeyleri sağladığ 1 görülmektedir. Ancak, programlanmış etkin madde salımı klasik yamalarla kolayca sağlanamamaktadır; doz boşalması gözlenebilmekte ya da salım yetersiz kalabilmektedir (8). Bu sorunun çözümü olarak, transdermal sisteme kimyasal bir geçiş arttırıcının eklenmesi veya salımı fiziksel ya da mekanik bir yol ile arttıran/kontrol eden transdermal cihazlardan yararlanarak salımın modifiye edilmesi mümkündür.

\section{Deriden Geçişi Arttırmaya Yönelik Yaklaşımlar}

Deriden verilebilecek etkin maddelerin/aktif ajanların sayısının arttırılabilmesi amacıyla deriden geçişi arttırmaya yönelik stratejiler geliştirilmiş ve bunlar temel olarak kimyasal, fiziksel ve mekanik yöntemler olmak üzere üçe ayrılmışlardır. Stratum corneum bariyerinden geçişi arttırmak üzere etkin maddenin ön ilaç halinde kullanılması ya da doygun çözeltisinin 
hazırlanmasından yararlanılabileceği gibi $(9,10)$; lipozom türevleri ve katı lipid partiküller de taşıyıcı olarak tek başına ya da elektriksel yöntemler ile kombine halde kullanılabilmektedirler (1118). Yine tek başına ya da diğer yöntemlerle kombine olarak kullanılabilen kimyasal penetrasyon arttırıcılar ise en sık başvurulan geçiş arttırma seçeneklerinden birisidir (19-24). Son yıllarda deneysel çalışmalarına daha sık rastlanan fiziksel yöntemler arasında; iyontoforez (4, 9, 20, 24-30), elektroforez $(4,25,30-35)$ sonoforez $(4,25,36-37)$ gibi elektriksel yöntemler; basınç dalgası $(5$, 38) gibi mekanik metodlar; mikroiğneler, sıv1 ya da toz jet enjektör sistemleri gibi iğnesiz yöntemler (39-43) yer almaktadır (Tablo 1). Bu derlemenin devamında ağırlıklı olarak fiziksel yöntemler ve bunlara ait ticari ürünlerden (klinik çalışmaları biten ya da devam eden) söz edilmektedir.

Tablo 1. Transdermal geçiş arttırma mekanizmaları ve örnekleri (3).

\begin{tabular}{|c|c|c|c|c|}
\hline $\begin{array}{l}\text { Taşıyıcı/İlaç } \\
\text { Etkileşmeleri }\end{array}$ & $\begin{array}{l}\text { Veziküller/ } \\
\text { Partiküller }\end{array}$ & $\begin{array}{c}\text { St. Corneum } \\
\text { modifikasyonu }\end{array}$ & $\begin{array}{c}\text { St. Corneum } \\
\text { atlatılması }\end{array}$ & $\begin{array}{l}\text { Elektriksel } \\
\text { metodlar }\end{array}$ \\
\hline $\begin{array}{l}\text {-İyon çiftleri ve } \\
\text { koaservatlar } \\
\text { - Ötektik sistemler } \\
\text { - Önilaç (prodrug) } \\
\text { seçimi } \\
\text { - Süper doygun } \\
\text { Çözeltiler }\end{array}$ & $\begin{array}{l}\text { - Lipozomlar ve analogları } \\
{ }^{*} \text { Transfersome } \\
{ }^{\circledR} \text { Etozom } \\
\text { *Niozomlar } \\
\text { - Katı lipid nanopartiküller } \\
\text { - Yüksek hızlı partiküller } \\
{ }^{*} \text { PowderJect }^{\circledR} \\
\text { *IntraJect }^{\circledR}\end{array}$ & $\begin{array}{l}\text { - Hidrasyon } \\
\text { Okluzif yama } \\
\text { - Kimyasal } \\
\text { arttırıcılar }\end{array}$ & $\begin{array}{l}\text { - Mikroiğne } \\
\text { düzenekleri } \\
{ }^{*} \text { Makroflux } \\
\text { *Dermaroller }^{\circledR} \\
\text { - Ablasyon } \\
\text { *PassPort } \\
\text { *ViaDerm }\end{array}$ & $\begin{array}{l}\text { - Basınç Dalgası } \\
\text { - Ultrason } \\
\text { - Elektroforez } \\
\text { - İyontoforez } \\
{ }^{*} \text { Glukowatch }^{\circledR} \\
{ }^{*} \text { Vyteris }^{\circledR} \\
{ }^{*} \text { E-Trans }^{\circledR} \\
\text { *Phoresor II }^{\circledR}\end{array}$ \\
\hline
\end{tabular}

\section{Transferzomlar (Transfersome ${ }^{\circledR}$ )}

Lipozomlar, niozomlar veya mikroemülsiyonlar gibi lipid-yapılı süspansiyonlar düşük riskli ilaç taşıyıcılar olup en önemli problemleri deri yüzeyinde kalmaları dolayısıyla etkin maddenin transferini etkili bir biçimde sağlayamamalarıdır. Bu problemi çözen ve Transfersome ${ }^{\circledR}$ (IDEA AG) adıyla patent alan transdermal ilaç taşıııı sistem elastik veziküllerin ilk örneklerindendir. Transferzomlar (deforme olabilen lipozomlar) fosfolipidler ile bitim (edge) aktivatörlerinden oluşur ve transkütan yol boyunca lokal hidrasyon gradyanı ile kuru deri yüzeyinden daha hidrate olan canlı dokulara doğru sürüklenerek deriye penetre olabilirler $(3,13,15,44)$. Böylelikle taşıyıcı deride yer alan porlardan organın biyolojik aktivitesi veya bariyer özelliklerini etkilemeden geçebilmektedirler. $\mathrm{Bu}$ penetrasyon mekanizması sayesinde transferzom taşıyıcılar deride 
konsantre ilaç depolanmasını sağlayabilmekte, maddeleri subkutan dokunun derinlerine ulaştırabilmekte veya sistemik dolaşıma verebilmektedir (13). Transferzomlar lipozom üretimine göre hazırlanabilmekte vezikül büyüklüğü basınçlı homojenizasyon, ultrasonikasyon veya diğer mekanik yöntemlerle ayarlanabilmektedir (44).

Değişik boyut ve lipofilik özelliğe sahip moleküllerin (lidokain, tetrakain, siklosporin, diklofenak, tamoksifen, vs) yüklendikleri transferzomlar ile deriden geçebildiği belirlenmiştir. Kalsitonin, insülin, $\alpha$-ve $\gamma$-interferon, Cu-Zn süperoksit dismutaz, serum albumini ve dekstran gibi polipeptidlerin transferzom taşıyıcılar ile başarılı olarak deriden geçişlerinin sağlandığ belirtilmiştir $(13,44)$.

\section{Katı Lipid Nanopartiküler Sistemler}

Katı lipid nanopartiküler sistemler (solid lipid nanoparticulate systems-SLN) geleneksel emülsiyonların avantajlarını da içeren, yüksek basınçlı homojenizasyon tekniği ile üretilen partiküler sistemlerdir. Çoğunlukla lipid yapılı maddelerden hareketle üretilmekte olup küçük çapları nedeniyle büyük bir spesifik yüzeye, küresel şekle ve uygun bir zeta potansiyeline sahiptirler. Prednizolon, retinol, koenzim Q10, güneş filtreleri ve esanslarda kullanım alanı buldukları belirtilmektedir (45-47).

\section{Mikroiğneler}

Hipodermik iğneler ile enjeksiyon veya infüzyon uygulamasının acı ve rahatsızlık verici olması transdermal verilişe yönelimi arttırmış, mikrofabrikasyon teknolojisinin kullanılmasıyla 1998'den itibaren transdermal etkin madde salım çalışmalarında mikroiğnelerin kullanımı önem kazanmaya başlamıştır $(48,49)$. Hipodermik iğneler ve transdermal yamaların kombinasyonundan oluşan mikroiğne sistemlerinde, iğneler çoğunlukla katı silikondan ya da metalden ( $\mathrm{NiFe}$ ) yapılmış, mikron boyutlarında $(10-100 \mu \mathrm{m})$ olup metal olanları sıvı akışını daha etkin biçimde sağlaması amacıyla içleri boş olarak da üretilmişlerdir. Transdermal yama üzerinde yer alan mikroiğneler deriden geçişte ana bariyeri oluşturan $10-15 \mu \mathrm{m}$ kalınlıktaki stratum corneum 'da mikroskopik delikler oluşturmakta ve bu bariyeri aşan etkin madde alt tabakalara geçebilmektedir $(48,49)$. Mikroiğneler, etkin madde verilişini sağlayacak derinliğe kadar ilerlemekte ancak sinirlere ulaşmadığından acı oluşturmamakta ve hasta uyuncunu da arttırmaktadır. Mikroiğnelerin kullanımında deri üzerinde delikler oluşturulduktan sonra transdermal yama uygulamas1 yaklaşımlardan biridir. Bunun yanı sıra bir elektrik akımı uygulaması da mümkündür. Diğer bir yaklaşım ise iğnelerin etkin madde ile kaplanması ve deri içersine etkin maddenin bir depo olmaksızın doğrudan uygulanmasıdır. Bu ikinci yaklaşımın bir diğer şekli ise etkin madde 
çözeltisine daldırılan iğneler ile cilt yüzeyinin kazınmasıdır. Mikroiğneler ile DNA, proteinler, oligonükleotidler ve nanopartiküllerin verilebileceği belirtilmektedir (39-43, 48-51).

\section{Iyontoforez}

İyontoforez yöntemi temel olarak iyonik (yüklü) ve polar etkin maddelerin deri yolu ile organizmaya verilişinde az miktarda ve fizyolojik olarak kabul edilebilir düzeyde elektrik akımının uygulanmasıdır. $\mathrm{Bu}$ metod deriden ilacın transportunu arttırmada itici güç olarak elektrik potansiyeli gradyanını kullanmaktadır. İyontoforezin etki mekanizmasının temelinde elektriğin genel prensibi olan, benzer yüklerin birbirini itmesi ve farklı yüklerin birbirini çekmesi yaklaşımı yatmaktadır. Bu mekanizmanın kullanıldığı cihazlar, elektrotlar (anot ve katot) ve bir elektrik kaynağından oluşmaktadır. Elektrot çevresinde benzer polaritede çözünmüş molekül elektromotor itme gücüyle doku içine doğru sürüklenmekte, nötral moleküller ise elektroosmotik su akısına bağl1 olarak ilerlemektedirler. İyontoforezin kullanımı sistemik iletimi kontrollü biçimde sunmasından, yüklü moleküller üzerindeki potansiyel etkinliğinden ve özellikle de peptidler, proteinler gibi büyük moleküllü aktif maddelerin geçişini arttırmasından dolayı çok avantajlıdır (3-4, 52-55).

Ters iyontoforez ise bir molekülün vücuttan iyontoforez yardımıyla geri ekstraksiyonudur (52). Bu yöntem tanıda biyolojik sıvıların non-invazif olarak örneklenmesine olanak sağlanabilir, örneğin kan numunesi alınmaksızın klinik uygulamalar yapılmasına olanak sağlayabilir. Ters iyontoforez ilk kez sistik fibrozis tanısı amacıyla kullanılmış (56) ve bu yöntemden yola çıkılarak başka maddelerin de kandan geri ekstraksiyonu üzerinde çalışmalar yapılmıştır (57-62).

\section{Elektroforez}

Elektroforez yüksek voltaj uygulanarak lipid tabaka membranlarında geçici olarak karışıklık meydana getirme işlevidir. Devamlı ve küçük bir akımın uygulandığı iyontoforezin tersine, bu yöntemde yüksek voltajlı bir akım nabız atımı şeklinde ve çok kısa bir süre için uygulanmakta ve tek başına ya da diğer geçiş arttırıcı yöntemlerle kombine edilerek transdermal yolla çeşitli moleküllerin (makromoleküllere varan çeşitli büyüklükteki moleküller, lipofilik, hidrofilik, yüklü veya nötral moleküllere) geçişine olanak sağlamaktadır. Yöntemin etkinliği elektriksel parametrelere ve aktif molekülün fizikokimyasal karakterine bağlıdır. In vivo uygulamalarda yüksek voltaj iyi tolere edilmekle beraber kas kontraksiyonu görülmektedir. Elektroforez genellikle 0,5-1,0 V'luk potansiyelin tabaka başına 0,01 - $10 \mathrm{~ms}$ arasında uygulanması ile gerçekleştirilir. Elektroforezin iyontoforez ile beraber kullanılması durumunda, hücrelerin belirgin bir elektrik akımına maruz kalması sonucu membran porları açılır ve makro moleküllerin hücreden geçişine olanak tanınmış olur. Bu şekilde transdermal yol ile protein ve oligonükleotid verilişi mümkün olmaktadir $(3,4,54,63-64)$. 


\section{Ultrason}

Etkin madde salımı sırasında kesintisiz olarak ya da deri üzerine ön uygulama şeklinde ultrason dalgası uygulanması ile insülin, interferon, eritropoetin gibi proteinlerin terapötik dozlarda deriden geçişi sağlanabilmektedir. Sonoforez ya da fonoforez adıyla da bilinen bu yöntemde 20 kHz gibi düşük frekanslı ultrason dalgaları kullanılır. Kesintisiz uygulamada hastanın bir ultrason cihazını takması gereklidir ve cihazla uygulanan ultrason şiddeti düşüktür (yaklaşık $1 \mathrm{~W} / \mathrm{cm}^{2}$ ). Ön uygulama şeklindeki ultrason ise, etkin madde verilişi öncesinde birkaç saat süreyle deriyi yüksek geçirgenlik gösterecek hale getirmek amacıyla kullanılır. Terapötik amaçla kullanılan ultrason piezoelektrik disk üzerine hızlı biçimde voltaj değiştiren ve güç çevirici olarak adlandırılan bir mekanizmanın ilavesi ile oluşmaktadır. Güç çeviricideki hareket ile voltajın hızla değişmesi sonucu yüksek frekanslı basınç dalgası (ultrason) oluşmaktadır. Etkin madde ise, ultrasonik cihazdan enerjiyi deriye ileten bir temas ajanı (coupling agent) sayesinde verilmektedir. Ultrason dalgaları ile deride oluşan termal, mekanik ve kimyasal değişimler sonucunda stratum corneum ' da keratinositlerde kavitasyon (oyuk oluşumu) meydana gelmekte ve oluşan kavitasyon hücre içi permeasyonun artmasına, hızlı bir biçimde geri dönüşümlü hücre hasarına neden olmaktadır (37, $65-66)$.

\section{Basınç dalgaları}

Lazer tarafından üretilmiş olan basınç dalgaları, optik kırılma, termal soyma (ablasyon) ve absorbe edilen ortamı hızla 1sıtma (termoelastik jenerasyon) mekanizmalarını birlikte kullanır (5). Böylece, stratum corneum ve ek olarak da hücre membranının geçirgenliğini arttırabilir. Basınç dalgaları fotomekanik etki yoluyla geçiş arttıran tek mekanizmadır. Fotomekanik etkiler arasında kavitasyon, mikro-akım (microstreaming) ve basınçlı sıv1-akımı (jet) oluşumu da sayılabilmektedir. Bunlardan termal soyma basınç dalgası üretmek için güvenli bir yoldur. Bu metodta lazer radyasyonu hedef materyalin küçük parçalara ayrılmasını sağlar ve bu parçalar hedef yüzeyinden süpersonik bir hızla uzaklaşırlar. Basınç dalgasının pik basıncı, doğma zamanı ve süresi gibi özellikleri lazer parametrelerine bağlıdır (dalga boyu, atım süresi ve akı). Basınç dalgası oluşturmanın; "lithotripter" yardımıyla vücut dışında (ekstrakorporeal) şok dalgası oluşturmak veya şok dalgası tüpleri gibi enerjiler içeren farklı yolları da vardır; tüm bu yöntemler yüksek genlikli basınç dalgaları oluşturur ve etkin madde verilişi için kullanılabilirler. Özellikle şok dalgası tüplerinin transdermal olarak kullanımı belirtilmiştir $(5,38)$. Basınç dalgası stratum corneum 'da geçici bir süre için yeterli geçirgenlik sağlar ve makro moleküllerin dermis ve epidermisten difüzyonla geçişine izin verir. Basınç dalgası uygulaması sırasında herhangi bir ağrı ya da rahatsızlık görülmemiştir ve stratum corneum un bariyer fonksiyonu da tekrar eski haline dönmektedir (5). 


\section{MODERN TRANSDERMAL TERAPÖTIK SISTEMLERIN TEDAVIDE KULLANIM ALANLARI ve TİCARİ ÜRÜNLER}

Transdermal terapötik sistemler (TTS) üzerinde yapılan yıllar süren çalışmalar sonucu tedavide kullanılabilecek sistemler ticari ürün olarak geliştirilmiştir. Bunlardan 2009 yılı itibariyle piyasada bulunan sistemler, içerdikleri etkin maddeler ve üretici firmaları Tablo 2'de yer almaktadir.

Tablo 2. Ticari ürün olarak bulunan transdermal terapötik sistemler (67).

\begin{tabular}{|c|c|c|}
\hline Ticari adı & Etkin madde & Firma \\
\hline Alora & Estradiol & Watson \\
\hline Climara & Estradiol & Bayer HLTHcare \\
\hline Estraderm & Estradiol & Novartis \\
\hline Estradiol & Estradiol & Mylan \\
\hline Vivelle-Dot & Estradiol & Novartis \\
\hline Menostar & Estradiol & Bayer HLTHcare \\
\hline Climara Pro & Ethinyl estradiol/levonorgesterol & Bayer HLTHcare \\
\hline Ortho Evra & Ethinyl estradiol/norelgestomin & Ortho Mcneil \\
\hline Combipatch & Ethinyl estradiol/norethindrone & Novartis \\
\hline Catapress & Clonidine & Boehringer Ingelheim \\
\hline Oxytrol & Oxybutinin & Watson \\
\hline Duragesic & Fentanyl & Alza \\
\hline Fentanyl TDS & Fentanyl & Mylan \\
\hline Fentanyl TDS & Fentanyl & Watson \\
\hline Fentanyl TDS & Fentanyl & Lavipharm \\
\hline Daytrana & Methylphenidate & Shire \\
\hline Nicoderm CQ & Nicotine & Sanofi Aventis USA \\
\hline Nicotine & Nicotine & Aveva \\
\hline Habitrol & Nicotine & Novartis \\
\hline Prostep & Nicotine & Aveva \\
\hline Minitran & Nitroglycerine & $3 \mathrm{M}$ \\
\hline NG TDS & Nitroglycerine & Mylan \\
\hline Nitrodur & Nitroglycerine & Key Pharms \\
\hline Nitroglycerin & Nitroglycerine & Hercon Labs \\
\hline Nitroglycerin & Nitroglycerine & Kremers Urban \\
\hline EMSAM & Selegiline & Somerset \\
\hline TD Scop & Scopolamine & Novartis \\
\hline Androdrem & Testosterone & Watson \\
\hline Exelon & Rivastigmine & Novartis \\
\hline Neupro & Rotigotine & Schwartz Pharma \\
\hline
\end{tabular}




\section{Ölçülü Doz Transdermal Sprey $\left(M_{D T S}{ }^{T M}\right)$}

Estradiol içeren MDTS $^{\mathrm{TM}}$ (Metered Dose Transdermal Spray) Victorian Eczacılık Koleji tarafından geliştirilmiş ve Acrux Ltd. (Avusturalya) tarafından piyasaya sunulmuştur. MDTS ${ }^{\mathrm{TM}}$ pasif ve non-okluzif salım sağlayan mikro-dozlu uçucu bir sistemdir (68-70). Sistem deri yüzeyine püskürtüldügünde uçucu olan ve olmayan çözücülerden oluşan çözücü karışımı buharlaşır, deri üzerinde bir gözle görülmeyen depo oluşur (Patchless Patch ${ }^{\mathrm{TM}}$ Delivery, Acrux Ltd) ve Across ${ }^{\mathrm{TM}}$ (Acrux Ltd) adıyla patentli kimyasal penetrasyon arttırıcı yardımı ile etkin madde stratum corneum `dan hızla penetre olur (68-70). MDTS $^{\mathrm{TM}}$ çözücü sistemindeki hızlı kuruyan uçucu bileşen uygulama bölgesinde, alan başına düşen hacmi kesin olarak tanımlamaya olanak sağlar. Ayrıca, deri üzerinde taşıyıcı fazlası kalmaksızın homojen bir dağılım elde edilir. Bu şekilde kesin bir dozlama yapmak mümkün olmaktadır. Sistemdeki uçucu olmayan çözücü ise etkin maddenin buharlaşma sırasında çökmesini engeller. Bu çözücü stratum corneum dan hızlı bir şekilde geçebilmeli ve interselüler lipid yapısı üzerinde etkili bir permeasyon arttırıcı olmalıdır. Bu tür bir salım sistemi stratum corneum üzerinde gözle görünmeyen bir etkin madde ve penetrasyon arttırıcı deposu oluşturmakta ve etkin madde buradan sistemik dolaşıma yavaşça absorbe olmaktadır. $\mathrm{Bu}$ şekildeki her bir uygulamayla 2-4 günlük salım süresi sağlanmaktadır (68).

\section{D-TRANS Teknoloji}

D-TRANS ${ }^{\circledR}$ transdermal terapötik sistemleri ALZA Şirketi (Mountain View, CA) tarafından biyoyararlanım arttırmak, dozlama sıklığını azaltmak, kullanım kolaylığı ve kontrollü etkin madde verilişini sağlamak amacıyla geliştirilmiş sistemlerdir $(52,71)$.

D-TRANS ${ }^{\circledR}$ transdermal terapötik sistemler, yama tarzında deri yüzeyine yapıştırılan küçük adezif bandajdan etkin maddenin hız kontrollü olarak verilmesini sağlayan sistemlerdir. Fonksiyonları sürekli intravenöz veya subkutan infüzyona neredeyse eşdeğerdir. Büyük bölümü, esnek ve ince sırt materyalinin altında etkin madde deposu, bunun altında da hiz kontrol edici polimerik zar ve yapışkan kısımdan oluşmaktadır. Bu sistemlerde hız kontrol edici membran uygulamada etkin madde deposu ile deri arasında yer almakta ve etkin maddenin salımını kontrol etmektedir (52,71). Bu sistemin yer aldığ almaktadır. 
Tablo 3. ALZA D-TRANS ${ }^{\circledR}$ teknolojisi içeren TTS ürünler (71).

\begin{tabular}{llll}
\hline Ürün adı & Etkin madde & Sistem tipi & Depo tipi \\
\hline Testoderm TTS & Testosteron & Membran kontrollü & HPC \\
\hline Testoderm & Testosteron & Matriks kontrollü & EVAC \\
\hline Transderm Scop & Skopolamin & Membran kontrollü & PIB \\
\hline Transderm Nitro & Nitrogliserin & Membran kontrollü & Silikon \\
\hline Nicoderm CQ & Nikotin & Membran kontrollü & EVAC \\
\hline Duragesic & Fentanil & Membran kontrollü & HEC \\
\hline Estraderm & 17 B-estradiol & Membran kontrollü & HEC \\
\hline Catapress-TTS & Kklonidin & Membran kontrollü & PIB \\
\hline
\end{tabular}

\section{E-TRANS Teknoloji}

E-TRANS $^{\circledR}$ elektrotransport transdermal terapötik sistemleri yine ALZA Şirketi (Mountain View, CA) tarafından geliştirilmiş olup terapötik ajanın girişimsel bir yöntem kullanmadan elektrik potansiyeli ile deriye geçişini sağlayan sistemlerdir. Bu tip bir sistem iyonik iletim sağlayan elektrot çiftinden oluşan bir güç kaynağı içermekte ve deri ile temasta aktive olmaktadır (Şekil 1). Etkin madde çıkış hızı uygulanan elektrik akımı ile orantılı olduğundan önceden belirlenen dozlamanın yapılması sağlanabilmektedir $(52,72)$.

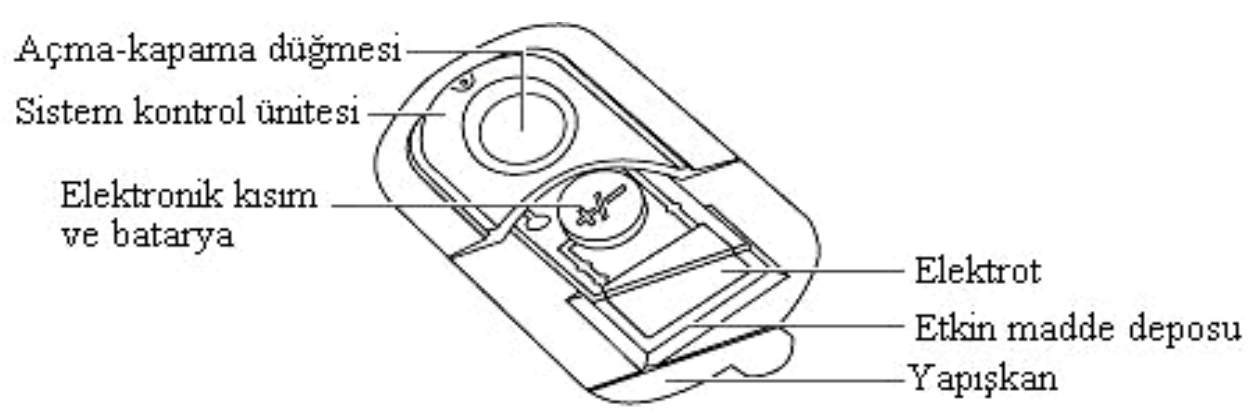

Şekil 1. E-TRANS ${ }^{\circledR}$ sistem ve bölümleri (52).

E-TRANS $^{\circledR}$ hem lokal hem de sistemik olarak kullanılabilmekte, deriden aktif transport ile etkin madde geçirmek üzere düşük düzeyde elektrik enerjisi ile çalışmaktadır. Sistem geniş bir ilaç grubunu deriden uygulamak amacıyla geliştirilmiştir. Aynı zamanda Macroflux ${ }^{\circledR}$ teknolojisi ile beraber de kullanılabilmektedir. Programlanabilir doz ve buna bağlı düşük maliyet, iğne kullanılmaması, yan etkilerin azaltılması ve hasta uyuncunun arttrr1ması ve de farklı etkin maddeler ile uygulanabilme gibi avantajları mevcuttur (52). 


\section{Macroflux ${ }^{\circledR}$ Teknolojisi}

Macroflux ${ }^{\circledR}$ teknolojisi ALZA tarafindan öne sürülen ve pek çok etkin maddenin transdermal verilişinde kullanılabilen bir sistemdir. Sistem paslanmaz çelik ya da titanyum bir mikroprojeksiyon dizilerinden oluşan bir düzenektir. Bu düzenek el ile deriye uygulandığında içerdiği mikroprojektörler deriye penetre olur ve derinin bariyer tabakasından protein, aşı gibi terapötik maddelerin geçişine izin veren yüzeysel bir geçiş yolu oluştururlar. Mikroprojeksiyon sistemi etkin madde ile kaplanabilmekte ya da bir etkin madde deposundan pasif difüzyon veya elektriksel yardım ile geçiş sağlamak üzere kombine halde kullanılabilmektedir $(73,74)$.

Macroflux ${ }^{\circledR}$ entegre sistemler etkin madde ya da aşı kaplı mikroprojeksiyon dizisinin esnek bir polimerik sırt materyaline yapıştırılması (Dry coated macroflux) ile elde edilebildiği gibi DTRANS $^{\circledR}$ ya da E-TRANS ${ }^{\circledR}$ sistemleri ile kombine halde de kullanılabilmektedir.

\section{Dermaroller $^{\mathrm{TM}}$ Teknolojisi}

Dermaroller ${ }^{\mathrm{TM}}$, stratum corneum tabakasını ağrısız delme amacıyla kullanılan bir mikroiğne teknolojisidir. Kozmetik amaçlarla, deride akne tedavisi ve yara iyileştirmede, kollajen uygulamalarında kullanılabildiği gibi, deriden transdermal yol ile etkin madde verilişinde medikal amaçlarla da uygulanabilmektedir $(75,76)$. Sistem silindirik bir gövdeye yerleşik tiplerine göre çeşitli sayı, boy ve çaplarda iğneler içermektedir (Şekil 2). Bu iğneler mekanik olarak dayanıklı ve toksik olmayan özelliktedir (76). Örneğin, Dermaroller ${ }^{\mathrm{TM}}{ }^{\prime}$ nin kozmetikte kullanılan C-8HE modelinde $200 \mu \mathrm{m}$ boy ve $70 \mu \mathrm{m}$ çaplı 192 adet iğne mevcut olup bu iğneli yüzeyin uygulama bölgesine 15 kere sürtülmesinden sonra bölgede $250 / \mathrm{cm}^{2}$ delik açıldı̆̆ı gösterilmiştir. Bu cihazın aşı uygulamalarında kullanımı belirtilmiştir. Yine C-8 modelinin deride $0,07 \mathrm{~mm}$ çaplı ve $0,13 \mathrm{~mm}$ derinlikte delikler açtığı, silindirik ana gövdenin kendisinin de bu deliklerden etkin maddenin içeri itilmesinde mekanik olarak etkili olduğu belirtilmiştir (75).

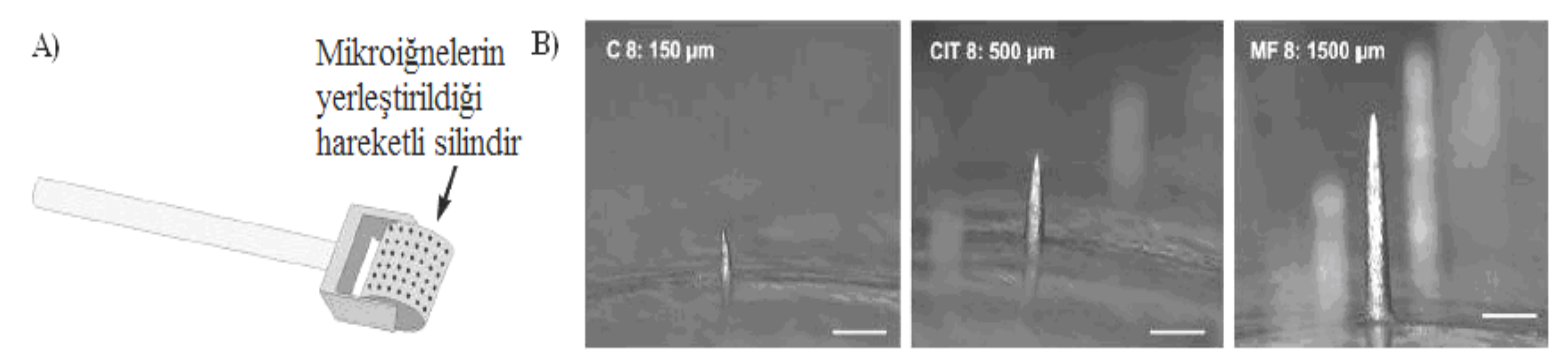

Şekil 2. Dermaroller ${ }^{\mathrm{TM}}{ }^{\prime}$ nin şematik şekli (A), değişik modellerindeki iğnelere ait görüntüler (B) (76). 


\section{İ̆nesiz Jet Enjektör}

İlk kez Antares Pharma, Inc. tarafından geliştirilen bu sistem küçük bir el feneri boyutunda helezonik bir yay şeklindedir. Enjektörü polikarbonat plastik şırınga ve pistondan oluşmakta ve şırınga kısmında geleneksel şırıngaların iğne taşıdığ yuvada küçük bir delik bulunmaktadır. Helezonik yay cihazı çalıştıracak enerjiyi sağlamakta ve sıvının hızla şırınga deliğinden salınmasını temin etmektedir. Bu şekilde oluşan "sıvı iğne" ile deri yüzeyinden yeterli basınçla penetrasyon sağlanmaktadır. Çalıştırmak için, yay üzerine sıkıştırma uygulandığında enjektör tek dozluk ilaç ile dolmakta ve deriye dik olarak tutularak tetik düğmesine basıldığında $0,5 \mathrm{~mL}$ hacimdeki ilaç ağrısız olarak uygulanmaktadır $(41,42,51,77)$. Şekil 3 te transdermal geçiş arttırmada kullanılan çeşitli mikro-cihazların çalışma şemaları yer almaktadır (50).

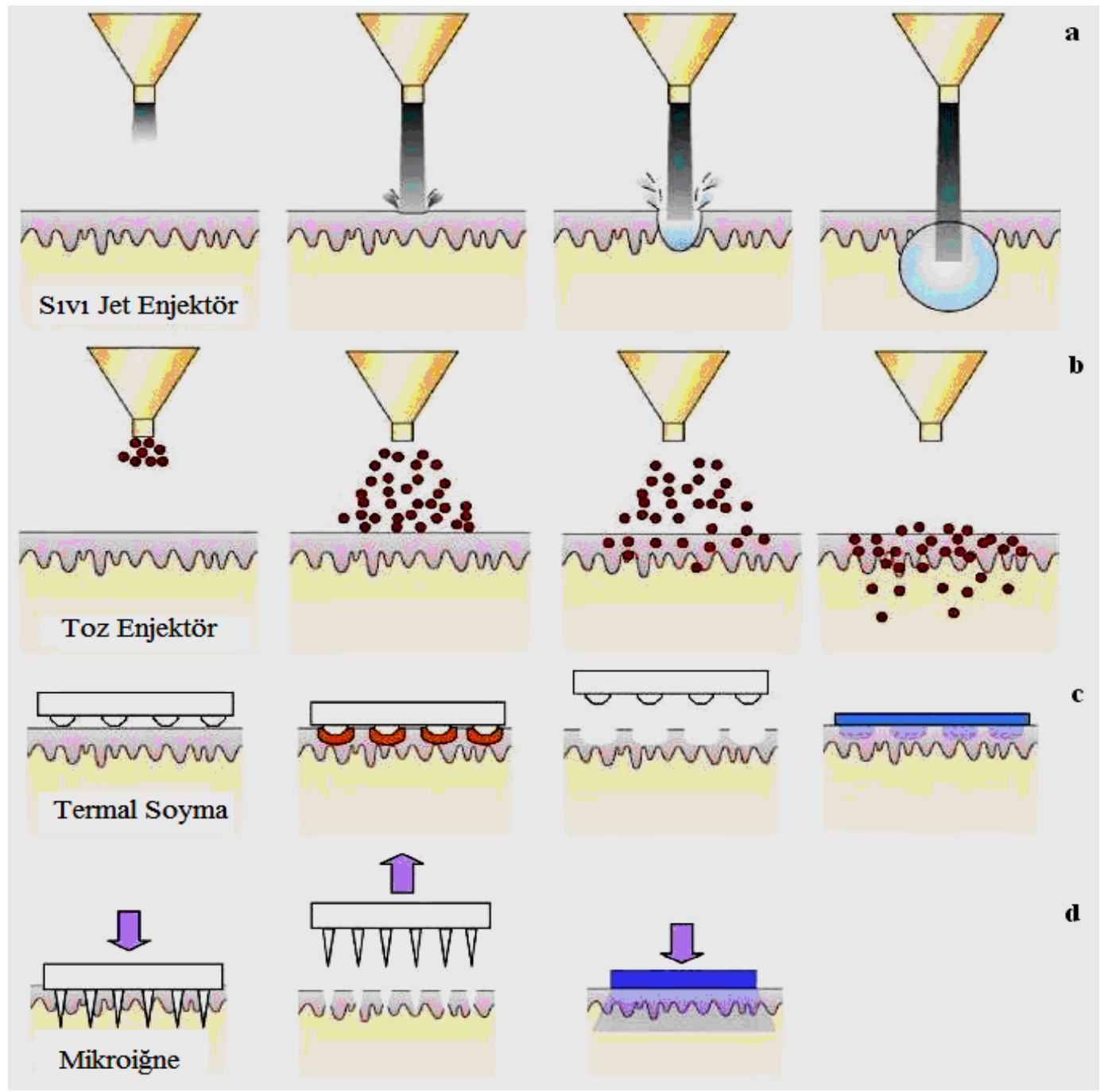

Şekil 3. Transdermal geçiş arttırmada kullanılan çeşitli mikro-cihazların çalışma şemaları (50); a)sıvı jet enjektör, b) toz enjektör, c) termal soyma, d) katı silikon mikroiğne 


\section{Dermal PowderJect Teknolojisi}

Çoğu hasta için, subkutan sıvı enjeksiyonunun yerini alan iğnesiz jet enjektörler bile tamamen ağrısız değildirler. Yama şeklindeki uygulamalar ağrısız olmakla beraber sadece küçük molekül ağırlıklı etkin maddeler için uygundur ancak PowderJect sisteminde molekül ağırlığı sınırlanmamıştır. PowderJect sistemi toz haldeki etkin maddenin yüksek hızda gaz akımı yardımıyla deriden itilmesidir. Bu iğnesiz yöntem nispeten ağrısız, kanamasız ve derideki hasarın ihmal edilebilir düzeyde olduğu bir sistemdir. PowderJect sistemi iki polikarbonat membran arasına yerleştirilmiş toz etkin madde ya da aşı içeren bir kasetten bir odacığa (boşluğa) etkin maddenin yüksek basınçta helyum gazının yardımıyla geçmesine izin veren bir metal gaz deposu içermekte ve bu basınçlı gaz yardımıyla etkin madde verilmesini sağlamaktadır $(3,51,78)$.

\section{Intraject Teknolojisi}

Intraject sıvı ilaçların ve aşıların subkutan enjeksiyonunda kullanılan ön dolumlu, tek kullanımlık iğnesiz bir sistemdir. Ölçülmüş miktarda sıvı ilacın, deriden subkutan dokunun altına iğnesiz olarak verilebilmesi için itici gaz kaynağı olarak kompakt nitrojen kullanmaktadır. Cihaz, işletici (aktivatör) ve kapsül olmak üzere iki kısımdan oluşmakta, işletici önden yüklenmiş gaz kaynağ1 ve tetik mekanizması içerirken, kapsül aseptik koşullarda birleştirilmiş bir etkin madde deposudur $(3,51,79)$.

\section{PassPort ${ }^{T M}$ Sistemi}

Althea Therapeutics tarafından geliştirilen PassPort ${ }^{\mathrm{TM}}$, insülin içeren ve 12 saat süre ile etkili olabilen transdermal bir yama ve yamayı uygulamakta kullanılan aplikatörden oluşan bir sistemdir (Tablo 4, Şekil 3, Şekil 4). Sistemin esası termal soymadır. Yamanın aplikatörünün içerdiği mikron boyutlu tungsten tellerden oluşan resistanslar aniden 1sınırlar (ohmik dirence dayalı) ve uygulama bölgesini de 1sıtırlar. Deri geçirgenliğini de bu şekilde arttırırlar. Hidromorfon $\mathrm{HCl}$, fentanil sitrat, apomorfin $\mathrm{HCl}$ gibi büyük moleküllü maddelerin bu sistemle verilmesi üzerinde çalışmalar bulunmaktadır. Hasta uyuncunu arttırdığı için enjeksiyona bir alternatif olarak geliştirilmiştir (3, $50,80)$. 


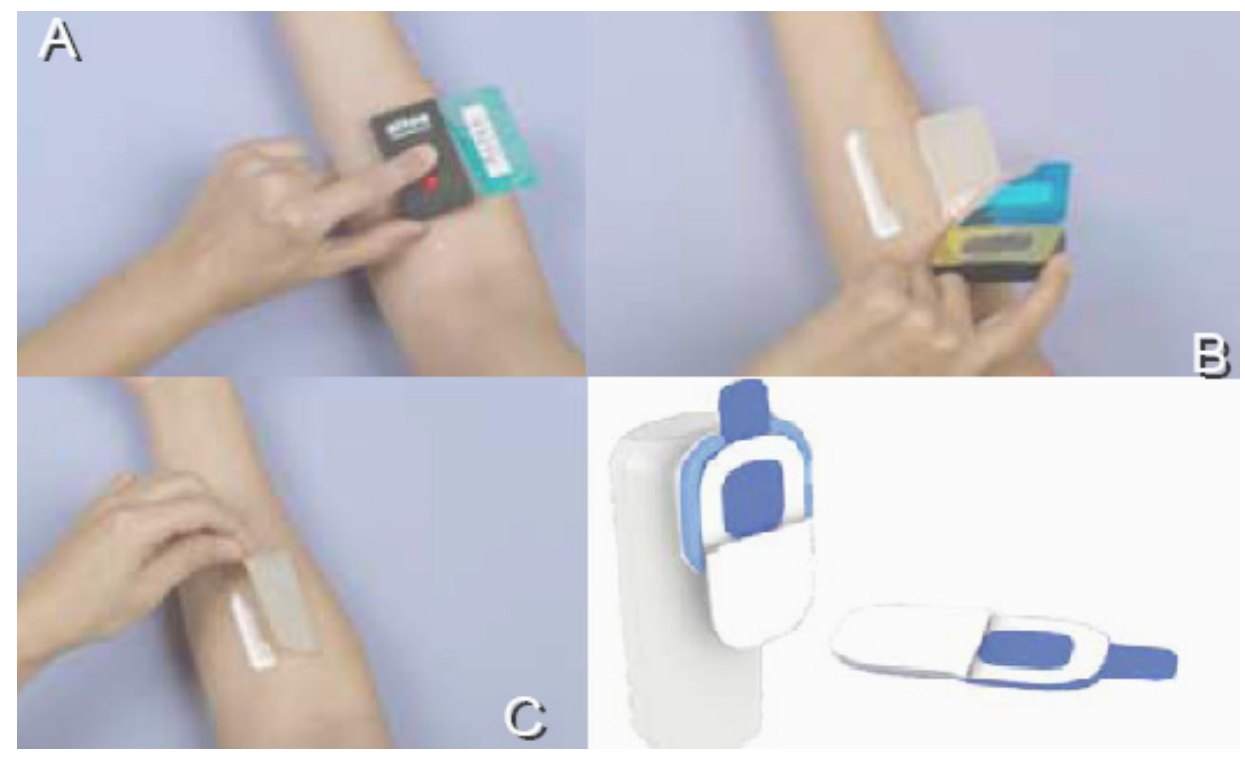

Şekil 4. PassPort ${ }^{\mathrm{TM}}$ insülin sistemi ve uygulanması (81).

Proteinlerin transdermal verilişinde kullanılan ticari mikro-cihaz örnekleri ve mikro-cihazları üzerindeki klinik çalışmaları devam eden bazı moleküller Tablo 4’te verilmiştir.

Tablo 4. Piyasada olan/çalışmaları süren, proteinlerin transdermal verilişinde kullanılan sistemler(80).

\begin{tabular}{ll}
\hline Ürün adı & Firma \\
\hline IntraJect & Aradigm \\
\hline MacroFlux ${ }^{\circledR}$ & Zosano Pharma \\
\hline PassPort $^{\mathrm{T}}$ Patch & Althea Therapeutics \\
\hline PyraDerm $^{\mathrm{TM}}$ & Apogee Technology \\
\hline TDS ${ }^{\circledR}$ & TransDermal Technologies, Inc. \\
\hline TPM-02 & Phosphagenics \\
\hline ViaDerm & TransPharma Medical, Ltd. \\
\hline & \\
\hline Inceleme altında olan $\ddot{\text { ürünler }}$ & \\
\hline Insulin & Althea Therapeutics \\
\hline Insulin & Phosphagenics \\
\hline Human growth hormone & Zosano Pharma \\
\hline Human growth hormone & TransPharma Medical, Ltd. \\
\hline Human parathyroid hormone (I-34) & TransPharma Medical, Ltd. \\
\hline
\end{tabular}

Tablo 5 te ABD piyasasında bulunan transdermal iyontoforez preparatları ve üretici firmalarından örnekler yer almaktadır (52). 
Tablo 5. ABD piyasasında bulunan transdermal iyontoforez preparatlarından örnekler (52).

\begin{tabular}{|c|c|c|c|}
\hline Üretici & Cihaz Markası & Electrot Markasi/Tampon sistemi & Depo Tipi \\
\hline Empi, Inc. & DUPEL & EBIE/ İyon değiştirici reçine & Polyester \\
\hline \multirow[t]{2}{*}{ Henley Intl. } & Dynaphor & Iotrode/ \% 0.9 tuz çöz.; \% $0.5 \mathrm{KHPO}_{4}^{-}$ & Koton/Rayon \\
\hline & & Medipad/yok & Hidrojel \\
\hline Iomed & Phoresor II & Trans Q1-Q2-QE/ $\mathrm{Ag}^{+}-\mathrm{AgCl}$ & Hidrojel/sponge \\
\hline \multirow[t]{2}{*}{ Life Tech, Inc. } & Iontophor PM/Dx & Meditode / \% 0.9 tuz çöz.; \% $0.5 \mathrm{KHPO}_{4}^{-}$ & Koton /Rayon \\
\hline & Microphor & & \\
\hline \multirow[t]{2}{*}{ General Medical Co } & Lectro Patch ${ }^{\circledR}$ & Lectro Patch/ istenmiyor & Polyester fleece \\
\hline & Drionic $\AA$ & Drionic/ istenmiyor & Polyester fleece/ yün \\
\hline Westor, Inc. & Sweat-Check ${ }^{\top M}$ & Pilogel $®$ disk / I.N.A. & Jel depo \\
\hline Scandipharm & CF Indicator ${ }^{\circledR}$ & Built-in/ $\mathrm{Ag}^{+}-\mathrm{AgCl}$ & Hidrojel \\
\hline
\end{tabular}

\section{GlucoWatch $^{\circledR}$-Glucowatch G2 ${ }^{\mathrm{TM}}$ Biographer}

Cygnus Inc. tarafından piyasaya sürülen ticari bir ürün olan G2 ${ }^{\mathrm{TM}}$ Biographer ters iyontoforez ile çalışarak kandan (+) yüklü glukozu toplamak amacıyla deriye çok düşük bir elektrik akımı uygulamakta ve (-) yüklü iyonların da (+) kutuptan kana doğru yönlenmesini sağlamaktadır. Oluşan iyon hareketi ile deriden toplanan glukoz molekülleri cihazın otosensöründeki iki jel toplama diskinin arasında birikmekte, toplanan glukozun düzeyi ile doğru orantılı olarak glukoz oksidaz ile katalizlenen bir reaksiyon sonucu elektriksel sinyal oluşmaktadır. G2 ${ }^{\text {TM }}$ Biographer bu sinyallerden yararlanarak glukoz miktarını hesaplamaktadır. Cihazın tedavide kullanıldığı alanlar, postprandyial hiperglisemi, nokturnal hipoglisemi ve beslenmeye bağlı hiperglisemidir (82-84).
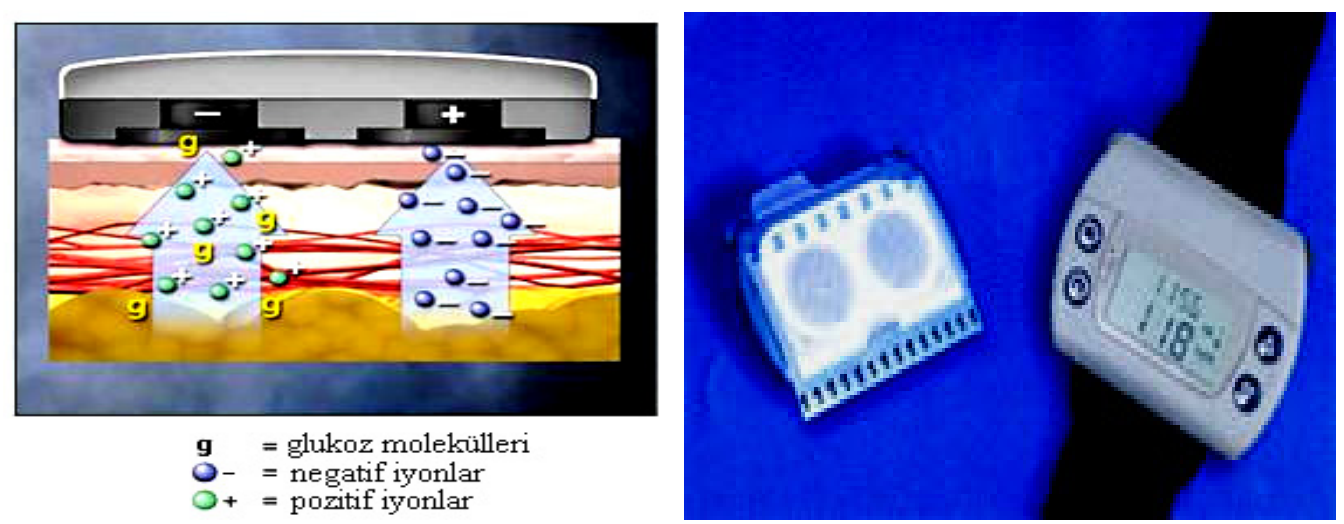

Şekil 5. GlucoWatch ${ }^{\circledR}$ sistemi ve uygulanması.

\section{Vyteris lidokain salım sistemi (Vyteris)}

$\mathrm{Bu}$ sistem ile pediatride katater takılmaksızın topikal anestezik uygulanması amaçlanmaktadır. Minimum ağrı ve hızlı dermal anestezi amacıyla geliştirilmiştir. İyontoforezin buradaki kullanımı elektrik alanını kullanarak etkin maddenin deriden geçişini arttırmak ve böylece hızlı bir "onset" etki elde etmektir. Vyteris sistemi ile lidokain ve epinefrin beraber verilmektedir. 
Burada epinefrinin rolü bölgedeki kan akışını azaltmak ve böylece lidokainin hızlı yıkımını önlemektir. Sistem önceden doldurulabilen esnek bir yama, takılabilen bir batarya ile enerji sağlayan kontrol ünitesi ve iç kısımdan oluşmaktadır. Yama monolitik bir yapı olup, içersinde lidokain $\mathrm{HCl} /$ epinefrin disperse edilmiştir. $\mathrm{Ag} / \mathrm{AgCl}$ elektrotlar bu hidrojel matris yapıya yerleştirilmiş olarak bulunmaktadır. Sistemin kontrol ünitesi ise LED arayüzey ve elektronik donanım için ev sahibidir. İlk klinik çalışmalar sonucunda sistem konfigürasyonu $5 \mathrm{~cm}^{2}$ anot, 2,5 $\mathrm{cm}^{2}$ katot, \% 10 lidokain, \% 0,1 epinefrin, 6-10 mm uygulama derinliği ve 10 dakika uygulama süresi şeklinde belirlenmiştir $(51,85)$.

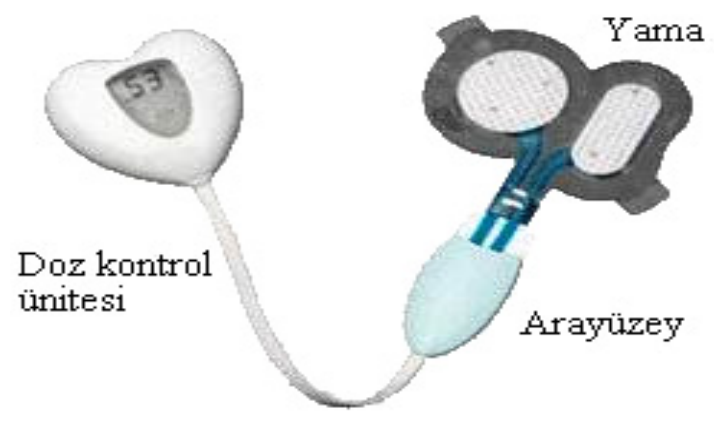

Şekil 6. Vyteris lidokain salım sistemi (85).

\section{Phoresor II ${ }^{\circledR}$}

Iomed Inc. tarafindan geliştirilen bu sistem (Phoresor Iontophoretic Drug Delivery System) lokal anestezik olarak lidokain ve epinefrin uygulanmasında kullanılan iyontoforez cihazlarından biridir. Lidokain $\mathrm{HCl}(\% 2)$ ve epinefrin $\left(\%\right.$ 0,001) topikal çözeltisi (Iontocaine ${ }^{\circledR}$ ) hidrojel elektrot (Gel Sponge ${ }^{\circledR}$ ya da Numby Stuff ${ }^{\circledR}$ ) yatağına emdirilmiş halde bulunur ve bu elektrot sistemi Phoresor cihazına bağlanarak düşük voltajlı elektrik akımı uygulanır. Özellikle pediatrik hastalarda katater ve enjektör kullanımını ortadan kaldırma avantajı olan, hızlı ve etkili bir anestezi uygulama yöntemidir $(52,86)$. 

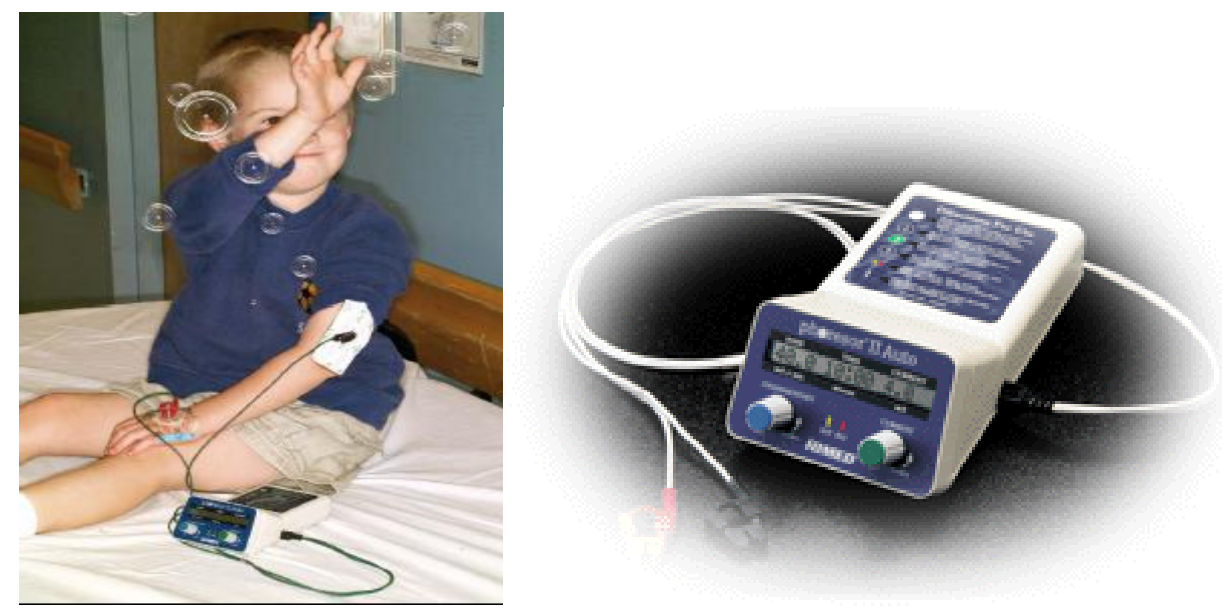

Şekil 7. Phoresor II sistemi (52).

\section{Webster Sweat Inducer}

Wescor Inc. (USA) tarafından geliştirilen bu sistem $2,8 \mathrm{~cm}$ çaplı jel disk şeklinde ve $\% 0,5$ pilokarpin içeren, elektrotlar yardımı ile 5-7 dakika süre ile $3 \mathrm{~mA}$ akım uygulayan bir iyontoforez cihazıdır. Cihazın önkol üzerine uygulanması ile deride pilokarpin stimulasyonu sağlanmakta, bu şekilde salgılanan ter iyontoforez uygulaması sonrasında, uygulama bölgesine yerleştirilen bir kolektör yardımı ile toplanmakta ve terin içerdiği klorür miktarı, osmolaritesi ölçülerek sistik fibrosiz tanısı konulmasında kullanılmaktadır $(52,87)$.

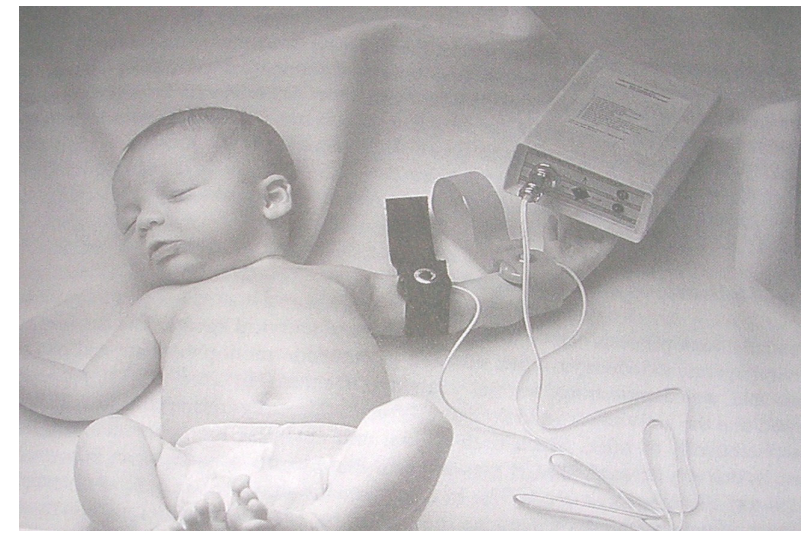

Şekil 8. Webster Sweat Inducer (52).

\section{SonoPrep ${ }^{\circledR}$}

Echo Therapeutics tarafından geliştirilen ultrason ile çalışan sonoforez cihazı SonoPrep ${ }^{\circledR}$ deriden girişimsel olmayan (non-invasif) ve ağrısız bir şekilde anestezi uygulamak üzere 
geliştirilmiştir. Cihazın, insülin ve heparin gibi büyük moleküllerin deriden verilişinde de kullanılabilmesi amacıyla klinik çalışmalar devam etmektedir. Sistem batarya, kontrol ünitesi, hasta referans sensörü, AC güç adaptörü ve dekontaminasyon tutucusundan oluşmaktadır. Kişisel kullanım ile kısa süreli olarak düşük frekanslı ultrason enerjisi uygulamaya olanak vermektedir $(88$, 89).

\section{Veteriner Tedavideki Transdermal Yaklaşımlar}

Veteriner tıpta topik ve transdermal ürünler sıklıkla kullanılmaktadır. Kedi, köpek, at gibi türlerin üzerinde fentanil yama uygulanmasına yönelik çalışmalar bulunmaktadır. Yine fipronil $\left(\right.$ TopSpot $^{\circledR}$, Frontline $^{\circledR}$ ), imadakloprid (Advantage ${ }^{\circledR}$ ) ve selamektin (Revolution ${ }^{\circledR}$ ) veteriner tipta pestisidler için topikal olarak uygulanan ticari yama preparatları arasında yer almaktadır $(90,91)$.

$\mathrm{Bu}$ preparatlarda etkinliğin arttırılması amacıyla kimyasal penetrasyon arttırıcıların tek başına veya iyontoforez, sonoforez gibi yöntemlerle kombine halde ve toz şeklindeki etkin maddelerin transdermal yoldan iğnesiz enjektör sistemleri ile uygulanması mümkündür. $\mathrm{Bu}$ çalışmaların bir örneği olarak, Poli-L-laktik asit mikrokürelerine model etkin maddenin ilave edildiği bir tabanca sistemi olan Helios ${ }^{\mathrm{TM}}$ gösterilebilir $(90,92)$.

\section{SONUÇ}

Modern transdermal terapötik sistemlerin geliştirilmesine yönelik araştırmaların son yıllarda giderek arttığı bilinmektedir. Bu sistemler, tedavideki başarısı, hasta uyuncu ve tedavide yer alan kişilere sunduğu avantajlar nedeniyle oral alıma alternatif olarak görülmektedir. Bu konudaki gelişmelerin önemi transdermal yoldan geçişi arttırmada kullanılan mekanizmaların derinin bariyer fonksiyonlarının üstesinden gelmesinde yatmaktadır. Çoğu mikro boyutta cihaz şeklinde üretilen bu transdermal sistemlere güvenlik açısından bakıldığında; ticari ürünlerinin az sayıda olduğu görülmektedir. Ticari ürünler ve Faz II veya Faz III durumundaki transdermal cihazların üzerinde yapılan klinik çalışmalar sonucunda sistemlerin genel olarak kabul edilebilir düzeyde güvenli bulunduğu, ancak bununla beraber uygulama sonrasında ağrı, deri iritasyonu, kanama ve hematom görülebildiği belirtilmektedir. Bu konudaki en güvenli sonuçların mikroiğneler ve soyma yöntemleri ile elde edildiği belirtilmiştir. Mikroiğneler ile enfeksiyon varlığı görülmeden orta dereceli deri iritasyonu olasıllğı mevcut olup soyma yöntemlerinin ise in vitro "Draize" iritasyon ve "Visual Analogue Scale" testleri sonucunda çok düşük düzeyde ağrı ve eritem meydana getirebileceği tespit edilmiştir. Sistemlerin tespit edilen olumsuzlukları üzerinde çalışılmakta ve ilerleyen teknoloji ile bu sistemlere ait ticari ürünlerin gelişmesi ve çeşitlenmesi beklenilmektedir. 


\section{KAYNAKLAR}

1. Pişkin, E., "Transdermal Sistemler" in Kontrollu İlaç Serbestleştiren Sistemler, Marmara Üniversitesi Eczacılık Fakültesi Yayınları, 1989.

2. Kalia, Y.N., Guy, R.H., "Modelling transdermal drug release" Adv. Drug Del. Rev. 48. 159172, (2001).

3. Barry, B.W., "Novel mechanisms and devices to enable successful transdermal drug delivery." Eur. J. Pharm. Sci. 14. 101-114, (2001).

4. Wang,Y., Thakur, R., Fan, Q., Michniak, B., "Transdermal iontophoresis: combination strategies to improve transdermal iontophoretic drug delivery." Eur. J. Pharm. Biopharm. 60. 179-191, (2005).

5. Doukas, A.G., Kollias, N., "Transdermal drug delivery with pressure wave" Adv. Drug Del. Rev. 56. 559-579, (2004).

6. Hekimoğlu Konur, S., "Perkütan absorpsiyonu in vivo inceleme yöntemleri". FABAD Farm. Bil. Der. 12. 26-38 (1987).

7. Barry, B.W., "Is transdermal drug delivery research still important today?" DDT, 6 (19). 967971, (2001).

8. Hadgraft, J. “ Dermal and Transdermal Delivery" in Modified Release Drug Delivery Technology, Rathbone, M.J., Hadgraft, J., Roberts, M.S. (eds.), Marcel Dekker, Inc., NewYork-Basel, 472-480 (2003).

9. Sung, K.C., Fang, J.Y., Hu, O.Y.P., "Delivery of nalbuphine and its prodrugs across skin by passive diffusion and iontophoresis" J. Controlled Rel. 67. 1-8, (2000).

10. Inoue, K., Ogawa, K., Okada J., Sugibayashi, K., “ Enhancement of skin permeation of ketotifen by supersaturation generated by amorphous form of the drug" J. Controlled Rel. 108. 306-318, (2005).

11. Matsuda, H., Arima, H., "Cyclodextrins in transdermal and rectal delivery" Adv. Drug Del. Rev. 36. 81-99, (1999).

12. Li, H., Li, S., Wang, Y., Yao H., Zhang, Y., "Effect of vehicles and enhancers on the topical delivery of cyclosporin A" Int. J. Pharm. 311. 182-186, (2006).

13. Cevr, G., "Lipid vesicles and other colloids as drug carriers on the skin." Adv. Drug Del. Rev. 56. $675-711,(2004)$. 
14. Gupta, P.N., Mishra, V., Rawat, A., Dubey, P., Mahor, S., Jain, S., Chatterji, D.P., Vyas, S.P., "Non-invasive vaccine delivery in transfersomes, niosomes and liposomes: a comparative study." Int. J. Pharm. 293. 73-82, (2005).

15. Elsayed, M.M.A., Abdallah, O.Y., Naggar, V.F., Khalafallah, N.M., "Deformable liposomes and ethosomes: mechanism of enhanced skin delivery" Int. J. Pharm. 322. 60-66, (2006).

16. Fang, J.Y., Fang, C.L., Liu, C.H., Su, Y.H., "Lipid nanoparticles as vehicles for topical psoralen delivery: Solid lipid nanoparticles (SLN) versus nanostructured lipid carriers (NLC)" Eur. J. Pharm. Biopharm. 70. 633-640, (2008).

17. Liu, W., Hu, M., Liu, W., Xue, C., Xu, H.,Yang, X.L., "Investigation of the carbopol gel of solid lipid nanoparticles for the transdermal iontophoretic delivery of triamcinolone acetonide acetate" Int. J. Pharm. 364. 135-141, (2008).

18. Pardeike, J. Hommoss, A., Müler, R.H., "Lipid nanoparticles (SLN, NLC) in cosmetic and pharmaceutical dermal products.” Int. J. Pharm. 366. 170-184, (2009).

19. Williams, A.C., Barry, B.W., "Penetration enhancers" Adv. Drug Del. Rev. 56. 603-618, (2004).

20. DeGraaff, A.M., Li, G.L., VanAelst, A.C., Bouwstra, J.A., "Combined chemical and electrical enhancement modulates stratum corneum structure" J. Controlled Rel. 90. 49-58, (2003).

21. Femenia-Font, A., Balaguer-Fernandez, C., Merino, V., Rodilla, V., Lopez-Castellano, A., "Effect of chemical enhancers on the in vitro percutaneous absorption of sumatriptan succinate" Eur. J. Pharm. Biopharm. 61. 50-55, (2005).

22. Ren, C., Fang, L., Ling, L., Wang, Q., Liu, S., Zhao, L.G., He, Z., "Design and in vivo evaluation of an indapamide transdermal patch" Int. J. Pharm. 370. 129-135, (2009).

23. Amnuaikit, C., Ikeuchi, I., Ogawara, K., Higaki, K., Kimura, T., "Skin permeation of propranolol from polymeric film containing terpene enhancers for transdermal use" Int. J. Pharm. 289. 167-187, (2005).

24. Pillai, O., Panchagnula, R., "Transdermal delivery of insulin from poloxamer gel: ex vivo and in vivo skin permeation studies in rat using iontophoresis and chemical enhancers" $J$. Controlled Rel. 89. 127-140, (2003). 
25. Fang, J.Y., Hwang, T.L., Huang, Y.B., Tsai, Y.H., "Transdermal iontophoresis of sodium nonivamide acetate V. Combined effect of physical enhancement methods." Int. J. Pharm. 235. 95-105, (2002).

26. Lopez, R.F.V., Bentley, L.B., Delgado-Charro, M.B., Guy, R.H., "Optimization of aminolevulinic acid delivery by iontophoresis" J. Controlled Rel. 88. 65-70, (2003).

27. İnal, Ö., Kılıçarslan, M., Arı, N., Baykara, T., "In vitro and in vivo transdermal studies of atenolol using iontohoresis" Acta Pol. Pharm.-Drug Res. 65 (1). 29-36, (2008).

28. Xu, Q., Ibrahim, S.A., Higuchi, W.I., Li, S.K., "Ion-exchange membrane asssited transdermal iontohoretic delivery of salicylate and acyclovir" Int. J. Pharm. 369. 105-113, (2009).

29. Takmaz, E.A., İnal, Ö., Baykara, T., "Studies on transdermal delivery enhancement of zidovudine" AAPS PharmSciTech. (10)1. 88-97, (2009). DOI: 10.1208/s12249-008-9179-9).

30. Prasad, R., Koul, V., Anand, S., Khar, R.K., "Effect of DC/mDC iontophoresis and terpenes on transdermal permeation of methotrexate: in vitro study." Int. J. Pharm. 333. 70-78, (2007).

31. Regnier, V., DeMorre, N., Jadoul, A., Preat, V., "Mechanisms of a phosphorothioate oligonucleotide delivery by skin electroporation" Int. J. Pharm. 184. 147-156, (1999).

32. Jiang, G., Zhu, D., Zan, J., Ding, F., "Transdermal drug delivery by electroporation: The effects of surfactants on pathway lifetime and drug transport." Chin. J. Chem. Eng. 15 (3). 397402, (2007).

33. Burgess, S., Zhao, Y.L., Sen, A., Wen Hui, S., "Resealing of electroporation of porcine epidermis using phospholipids and poloxamers" Int. J. Pharm. 336. 269-275, (1997).

34. Becker, S.M., Kuznetsov, A.V., "Thermal in vivo skin electroporation pore development and charged macromolecule transdermal delivery: a numerical study of the influence of chemically enhanced lower lipid phase transition temperatures" Int. J. Heat Mass Transfer 51. 2060-2074, (2008).

35. Wallace, M.S., Ridgeway, B., Jun, E., Schulteis, G., Rabussay, D., Zhang, L., "Topical delivery of lidocaine in healthy volunteers by electroporation, electroincorporation, or iontophoresis: an evaluation of skin anesthesia. Regional Anesth. Pain Med. 26 (3). 229-238, (2001).

36. Boucaud, A., Garrigue, M.A., Machet, L., Vaillant, L., Patat, F., "Effect of sonication parameters on transdermal delivery of insulin to hairless rats" J. Controlled Rel. 81. 113-119, (2002). 
37. Smith, N.B., Lee, S., Shung, K.K., "Ultrasound-mediated transdermal in vivo transport of insulin with low-profile cymbal arrays." Ultrasound in Med. \& Biol. 29 (8). 1205-1210, (2003).

38. Lee, S., McAuliffe, D.J., Kodama, T., Doukas, A.G., " In vivo transdermal delivery using a shock tube" Shock Waves. 10. 307-311, (2000).

39. Teo, A.L., Shearwood, C., Ng, K.C., Lu, J., Moochhala, S., "Transdermal microneedles for drug delivery applications." Materials Science and Engineering B. 132. 151-154, (2006).

40. Kendall, M., "Engineering of needle-free physical methods to target epidermal cells for DNA vaccination." Vaccine 24. 4651-4656, (2006).

41. Giudice, E.L., Campbell, J.D., "Needle-free vaccine delivery." Adv. Drug Del. Rev. 58. 6889, (2006).

42. Ding, Z., Verbaan, F.J., Bivas-Benita, M., Bungener, L., Huckriede, A., VanDerBerg, D.J., Kertsen, G., Bouwstra, J.A., "Microneedle arrays for the transcutaneous immunization of diphteria and influenza in BALB/c mice" $J$.Controlled Rel. (2009). Doi: 10.1016/j.jconrel.2009.01.025

43. Li, G., Badkar, A., Nema, S., Sekhar Kolli, C., Banga, A.J., "In vitro transdermal delivery of therapeutic antibodies using maltose microneedles" Int. J. Pharm. 368. 109-115, (2009).

44. Cevr, G., "Transfersomes: Innovative transdermal drug carriers" in Modified Release Drug Delivery Technology, Rathbone, M.J., Hadgraft, J., Roberts, M.S. (eds.), Marcel Dekker, Inc., NewYork-Basel, 533-546, (2003).

45. Müller, R.H., Wissing, S.A., "SLN and Lipopearls for topical delivery of active compounds and controlled release" in Modified Release Drug Delivery Technology, Rathbone, M.J., Hadgraft, J., Roberts, M.S. (eds.), Marcel Dekker, Inc., NewYork-Basel, 571-587, (2003).

46. Gasco, M. R., "Lipid nanoparticles:perspectives and challenges" Adv. Drug Del. Rev. 59. 6377-378, (2007).

47. Cengiz, E., Wissing, S.A., Müller, R.H.,Yazan, Y., "Sunblocking Efficiency of Various Ti2O-Loaded Solid Lipid Nanoparticle Formulations", Int.J.Cosm.Sci. 28. 371-378, (2006).

48. Prausnitz, M.R., Ackley, D.E., Gyory, J.R., "Microfabricated microneedles for transdermal drug delivery" in Modified Release Drug Delivery Technology, Rathbone, M.J., Hadgraft, J., Roberts, M.S. (eds.), Marcel Dekker, Inc., NewYork-Basel, 513-522, (2003). 
49. Sonakın, Ö., Karataş, A., "Mikrofabrikasyon teknolojisi ve ilaç taşıyıcı sistemler üzerinde uygulamaları." Ankara Ecz. Fak. Derg., 36 (1). 47-74, (2007).

50. Prausnitz, M.R., "Microneedles for transdermal drug delivery." Adv. Drug Del. Rev. 56. 581587, (2004).

51. Arora, A., Prausnitz, M.R., Mitragotri, S., "Micro-scale devices for transdermal drug delivery" Int. J. Pharm. 364. 227-236, (2008).

52. Singh, P., Maibach, H.I., "Iontophoresis in drug delivery: Basic principles and applications" Critical Rew. Ther. Drug Carr. Syst. 11 (2-3). 161-213, (1994).

53. Banga, A.J., "Iontophoretic transdermal delivery" in Electrically Assisted Transdermal and Topical Drug Delivery, Banga A.J. (ed.), Taylor and Francis, UK-USA, p.13-32, (1998).

54. Banga, A.J., "Electrically Assisted Transdermal Delivery of Drugs" in Handbook of Pharmaceutical Controlled Release Technology, Wise, D.L. (ed.), Marcel Dekker, 567-581, (2000).

55. Kalia, Y.N., Naik, A., Garrison, J., Guy, R.H., “Iontophoretic drug delivery” Adv. Drug Del. Rev. 56. 619-658, (2004).

56. Panchagnula, R., Pillai, O., Nair, V.B., Ramarao, P., "Transdermal iontophoresis revisited" Current Opinion in Chemical Biology. 4. 468-473, (2000).

57. Sekkat, N., Naik, A., Kalia, Y.N., Glikfelde, P., Guy, R.H., "Reverse iontophoresis monitoring in premature neonates: feasibility and potential" J. Controlled Rel. 81. 83-89, (2002).

58. Değim, İ.T., İlbasmış, S., Dundaroz, R., Oguz, Y., "Reverse iontophoresis: a non-invasive technique for measuring blood urea level" Pediatr. Nephrol. 18. 1032-1037, (2003).

59. Leboulanger, B., Guy, R.H., Delgado-Charro, M.B., "Non, invasive monitoring of phenytoin by reverse iontophoresis" Eur. J. Pharm. Sci. 22. 427-433, (2004).

60. Wascotte, V., Leboulanger, B., Guy, R.H., Delgado-Charro, M.B., "Reverse iontophoresis of lithium:electrode formulation using a thermoreversible polymer" Eur. J. Pharm. Biopharm. 59. 237-240, (2005).

61. Ching, C.T.S., Connolly, P., "Reverse iontophoresis: a non-invasive techique for measuring blood lactate level" Sensors and Actuators B. 129. 352-358, (2008). 
62. Anke, S., Jeanneret, F., Fathi, M., Hochstasser, D., Rudaz, S., Veuthey, J.L., Guy, R.H., Delgado-Charro, M.B., "Extraction of aminoacids by reverse iontophoresis in vivo" Eur. $J$. Pharm. Biopharm. 72. 226-231, (2009).

63. Banga, A.J., "Transdermal delivery by electroporation" in Electrically Assisted Transdermal and Topical Drug Delivery, Banga A.J. (ed.), Taylor and Francis, UK-USA, p.95-107, (1998).

64. Prausnitz, M.R., "A practical assessment of transdermal drug delivery by skin electroporation" Adv. Drug Del. Rev. 35. 61-76, (1999).

65. Mitragotri, S., Kost, J. "Low frequency sonophoresis: A review" Adv. Drug Del. Rev. 56. 589-601, (2004).

66. Machet, L., Boucaud, A., "Phonophoresis: efficiency, mechanism and skin tolerance. Int. J. Pharm. 243: 1-15, (2002).

67. Farahmand, S., Maibach, H.I., "Transdermal drug pharmacokinetics in man: interindividual variability and partial prediction" Int J. Pharm. 367. 1-15, (2009).

68. Morgan, T.M., Reed, B.L., Finnin, B.C., “ Metered-Dose Transdermal Spray (MDTS)) in Modified Release Drug Delivery Technology, Rathbone, M.J., Hadgraft, J., Roberts, M.S. (eds.), Marcel Dekker, Inc., NewYork-Basel, 523-531, (2003).

69. Fraser, I.S., Weisberg, E., Kumar, N., Kumar, S., Humberstone, A.J., McCrossin, L., Shaw, D., Tsong, Y.Y., Sitruk-Ware, R., "An initial pharmacokinetic study with a Metered Dose Transdermal System for delivery of the progestogen Nestorone as a possible future contraceptive" Contraception 76. 432-438, (2007).

70. Thomas, B.J., Finnin, B.C., “The transdermal revolution” DDT . 9 (16). 697-703, (2004).

71. Padmanabhan, R., Gale, R.M., Phipps, J.B., Van Osdol, W.W., Young, W. "D-TRANS technology" in Modified Release Drug Delivery Technology, Rathbone, M.J., Hadgraft, J., Roberts, M.S. (eds.), Marcel Dekker, Inc., NewYork-Basel, 481-498, (2003).

72. Phipps, J.B., Padmanabhan, R.V., Young, W., Panos, R., Chester, A.E., "E-TRANS technology" in Modified Release Drug Delivery Technology, Rathbone, M.J., Hadgraft, J., Roberts, M.S. (eds.), Marcel Dekker, Inc., NewYork-Basel, 499-511, (2003).

73. Cormier, M., Daddona, P.E., "Macroflux technology for transdermal delivery of therapeutic proteins and vaccines" in Modified Release Drug Delivery Technology, Rathbone, M.J., Hadgraft, J., Roberts, M.S. (eds.), Marcel Dekker, Inc., NewYork-Basel, 590, (2003). 
74. Lin, WQ., Cormier, M., Samiee, A., Griffin, A., Johnson B., Teng, C-L., Hardee, G.E., Daddona, P.E., "Transdermal delivery of antisense oligonucleotides with Microprojection patch (Macroflux) technology” Pharm. Res. 18 (12). 1789-1792, (2001).

75. http://www.dermaroller.co.nz

76. Badran, M.M., Kuntsche, J., Fahr, A., "Skin penetration enhancement by a microneedle device (Dermaroller) in vitro: Dependency on needle size and applied formulation" Eur. $J$. Pharm. Sci. 36. 511-523, (2009).

77. Pass, F., Hayes, J., "Needle free drug delivery" in Modified Release Drug Delivery Technology, Rathbone, M.J., Hadgraft, J., Roberts, M.S. (eds.), Marcel Dekker, Inc., NewYork-Basel, 601-603, (2003).

78. Bellhouse, B.J., Kendall, M.A.F., "Dermal PowderJect Device" in Modified Release Drug Delivery Technology, Rathbone, M.J., Hadgraft, J., Roberts, M.S. (eds.), Marcel Dekker, Inc., NewYork-Basel, 607-61, (2003).

79. Levy, A., "IntraJect: Prefilled, disposable, needle-free injection of liquid drugs and vaccines" in Modified Release Drug Delivery Technology, Rathbone, M.J., Hadgraft, J., Roberts, M.S. (eds.), Marcel Dekker, Inc., NewYork-Basel, 619-631, (2003).

80. Moeller, E.H., Jorgensen, L., "Alternative routes of administration for systemic delivery of protein pharmaceuticals" Drug Discovery Today: Technol. (2008), doi: 10.1016/j.ddtec.2008.11.005.

81. www.alteatherapeutics.com/mediacoverage/OnDrugDelivery_Final.pdf

82. Pickup, J.C., Hussain, F., Evans, N.D., Sachedina, N., "In vivo glucose monitoring: the clinical reality and promise." Biosensors and Bioelectronics. 20 (10). 1897-1902, (2004).

83. Tura, A., Maran, A., Pacini, G., "Non-invasive glucose monitoring: assessment of Technologies and devices according to quantitative criteria” Diabetes Res. Clin. Pract. 77. 1640, (2007).

84. Montagnana, M., Caputo, M., Giavarina, D., Lippi, G., "Overwiev on self-monitoring of blood glucose" Clinica Chimica Acta. 402. 7-13, (2009).

85. Zempsky, W.T., Sullivan, J., Paulson, D.M., Hoath, S.B., "Evaluation of a low-dose lidokaine iontophoresis system for topical anaesthesia in adults and children: a randomized, controlled trial" Clinical Ther. 26 (7). 1110-1119, (2004). 
86. Naik, A., Kalia Y.N., Guy, R.H., "Transdermal drug delivery: overcoming the skin's barrier function" PSTT. 3 (9). 318-324, (2000).

87. Barben, J., Amman, R.A., Metlagel, A., Schoeni, M.H., "Conductivity determined by a new sweat analyzer compared with chloride concentrations for the diagnosis of cyctic fibrosis" The J. Pediatrics. Feb. 183-188, (2005).

88. Ferrera, K.W., "Driving delivery vehicles with ultrasound" Adv. Drug. Del. Rew. 60. 10971102, (2008).

89. http://www.echotx.com/SonoPrep+Drug+Delivery

90. Magnusson, B.M., Walters, K.A., Roberts, M.S., "Veterinary drug delivery: potential for skin penetration enhancement" Adv. Drug Del. Rev. 50. 205-227, (2001).

91. Riviere, J.E., Papich, M.G., "Potential and problems of developing transdermal patches for veterinary applications" Adv. Drug Del. Rev. 56. 175-203, (2001).

92. Mills, P.C., Cross, E.S., "Transdermal drug delivery: basic principles for the veterinarian" The Veterinary Journal. 172. 218-233, (2006).

Received: 20.04.2009

Accepted: 20.05.2009 